Medger, K., Chimimba, C.T. and Bennett, N.C. 2016. Is reproduction of male eastern rock sengis (Elephantulus myurus) from southern Africa affected by photoperiod? Canadian Journal of Zoology 94: 747-752. dx.doi.org/10.1139/cjz-2016-0132

\title{
Is reproduction of male eastern rock sengis (Elephantulus myurus) from southern Africa affected by photoperiod?
}

\author{
K. Medger ${ }^{1 *}$, C.T. Chimimba ${ }^{2}$, N.C. Bennett ${ }^{3}$ \\ ${ }^{1}$ Department of Zoology and Entomology, University of Pretoria, Private Bag X20, Hatfield, 0028 \\ South Africa, katarina@nzg.ac.za \\ ${ }^{2}$ DST-NRF Centre of Excellence for Invasion Biology (CIB), Department of Zoology and Entomology, \\ University of Pretoria, Private Bag X20, Hatfield, 0028 South Africa, ctchimimba@zoology.up.ac.za
}

${ }^{3}$ Department of Zoology and Entomology, University of Pretoria, Private Bag X20, Hatfield, 0028 South Africa, ncbennett@zoology.up.ac.za

*corresponding author and current address of Katarina Medger: National Zoological Gardens of South Africa, 232 Boom Street, Pretoria, P.O Box 754, Pretoria, 0001, South Africa,

katarina@nzq.ac.za,Tel.: +27 (0) 123392745

\begin{abstract}
Many mammals use the change in day-length to time physiological and behavioural activities on a seasonal basis. Particularly mammals from temperate regions use photoperiod to regulate reproductive functions; however, information on the role of photoperiod in small mammals from the tropics and sub-tropics is scarce. We studied the response of the reproductive system of male eastern rock sengis (Elephantulus myurus) from southern Africa to photoperiods of differing length. Elephantulus myurus breeds seasonally during the spring and summer months of the southern hemisphere despite its subtropical distribution. It is one of only three sengi species known to breed seasonally. Fourteen male E. myurus were subjected to either long-day (LD; 16L:8D) or short-day (SD; 8L:16D) photoperiods and the photoperiodic effects on the testes, testosterone concentration and body mass were examined. Testicular volume and mass, seminiferous tubule diameter as well as body mass were not significantly different between LD and SD conditions. However, plasma testosterone concentration was significantly lower in males on LD compared to SD photoperiods. Male E. myurus may not use photoperiod as a cue to control seasonal reproductive changes. Other environmental factors such as temperature, rainfall, food abundance or social factors are possibly influencing seasonal reproduction in this species.
\end{abstract}

Keywords: Elephantulus myurus, eastern rock sengi, day-length, seasonal reproduction, environmental cues, Macroscelidea, southern Africa

\section{Introduction}

In seasonal environments, resources and ultimately energy varies annually and, therefore, mammals breed during the most favourable conditions. In contrast, at times of extreme energy shortage, for example, during winter, energy may be required for other important functions such as cell maintenance and thermoregulation, and as a consequence breeding is put on hold and the gonads regress (Bronson 1985). Consequently, mammals need to be able to anticipate and ultimately prepare 
for recurring annual environmental changes in order to increase their survival and reproductive success (Bradshaw and Holzapfel 2007). Several mechanisms have been identified which enable an animal to envisage environmental changes and to adapt its physiology and behaviour even before new conditions arise. The direct activation of the required changes by an environmental cue, such as photoperiod, is widely applied by mammals and most commonly found in small mammals with short longevities (Paul et al. 2008). Instead, many long-lived mammals use an endogenous circannual clock to keep track of the seasons, which is often entrained by photoperiod (Paul et al. 2008). In particular, the reproductive biology of many seasonally breeding mammals appears to depend on photoperiodic time-measuring systems. However, photoperiod is more reliable at higher than lower latitudes because photoperiodic changes are more marked at these latitudes. Photoperiodic time-measuring systems are, therefore, mostly used by mammals from temperate regions, whereas other environmental factors may shape reproduction at latitudes below $30^{\circ}$ (Bronson 1985).

Much research on photoperiodic timemeasuring systems and reproductive seasonality has been undertaken on northern hemisphere rodents (Bronson 2009). Many temperate species such as deer mice (Lynch et al. 1981; Nelson et al. 1997), voles (Nelson et al. 1989) and lemmings (Weil et al. 2006), have been found to be reproductively photoresponsive although the extent of the response may differ between the sexes, populations and individuals. In the deer mouse (Peromyscus maniculatus), responsiveness to photoperiod increases with higher latitude (Dark et al. 1983). In contrast, responsive and non-responsive morphs have been found in a population of the northern red-backed vole (Myodes rutilus) (Dark et al. 1983; Stevenson et al. 2009). Most sub-tropical and tropical rodents breed opportunistically and use other environmental factors besides photoperiod to time reproduction. For example, the Aztec mouse (Peromyscus aztecus), which occurs below $20^{\circ} \mathrm{N}$, does not show a reproductive response to photoperiod, but housing males with females resulted in an increase in male gonad mass, sperm counts and testosterone concentration (Demas and Nelson 1998). In southern Africa, the four-striped field mouse (Rhabdomys pumilio) has been found to be reproductively non-responsive to photoperiod, but temperature and food quantity affect reproduction of males and females of this species (Jackson and Bernard 1999, 2001). In contrast, other southern African rodents have been found to regress their reproductive systems under short-day photoperiods (Muteka et al. 2006; Medger et al. 2012a).

The reproductive physiology of many small African mammals is still largely unknown and although African rodents are underrepresented in such research, the situation for non-murid mammals is even more depauperate. Recently, the greater red musk shrew (Crocidura flavescens) from South Africa was found to be reproductively photoresponsive (Hoole et al. 2016). We are not aware of any other studies investigating photoperiod as a reproductive cue in other southern African small mammals besides those on rodents. Similar to the findings by Hoole et al. (2016), the tropical musk shrew (Suncus murinus) from Asia is reproductively photoresponsive, although it is not a seasonal breeder (Rissman et al. 1987). On the other hand, bats and flying foxes do not seem to use photoperiod as a cue to regulate seasonal reproduction (O'Brien et al. 1993; Heideman and Bronson 1994). The aim of the present study is to investigate the reproductive response to differing photoperiods in the male eastern rock sengi (Elephantulus myurus) by examining gonadal development and plasma testosterone concentrations in males subjected to either long-day (LD) or short-day (SD) photoperiods. 
Members of the order Macroscelidea, usually referred to as elephant-shrews or sengis, are endemic to Africa (Skinner and Chimimba 2005). Elephantulus myurus is insectivorous and feeds mainly on ants and termites (Churchfield 1987). Like most sengis, E. myurus is monogamous (Ribble and Perrin 2005) and females almost always give birth to twins, which are highly precocial (van der Horst 1946). Elephantulus myurus reproduces seasonally with a distinct breeding season from August until January, spanning the southern hemispheres' warm and wet spring and summer months. The gonads of both males and females regress during the cold and dry autumn and winter months (Medger et al. 2012b). To date, there are very few studies that have investigated the cues, which control seasonal reproduction in the Macroscelidea. Neal (1995) suggested that reproduction may be regulated by photoperiod in the seasonally breeding Northern African sengi (E. rozeti) and in $E$. myurus. Following this suggestion, male $E$. myurus may be reproductively photoresponsive and we assumed that the testes are regressed and plasma testosterone concentrations reduced in males subjected to SD in comparison to LD photoperiods. This hypothesis is strengthened by the finding that rodents, inhabiting the same habitat as $E$. myurus, such as the Namaqua rock mouse (Micaelamys namaquensis) and the spiny mouse (Acomys spinosissimus), are reproductively photoresponsive (Muteka et al. 2006; Medger et al. 2012a).

\section{Materials and Methods Study animals}

A total of 14 male E. myurus were collected at the Goro Game Reserve $\left(22^{\circ} 58^{\prime} \mathrm{S}, 22^{\circ} 57^{\prime} \mathrm{S}\right.$; $29^{\circ} 25^{\prime} \mathrm{E}, 29^{\circ} 24^{\prime} \mathrm{E}$ ) in the Soutpansberg region, Limpopo Province, South Africa in February $(n=$ $7)$, April $(n=6)$ and July $(n=1)$ 2009. The animals were trapped overnight with Sherman live traps (H. B. Sherman Traps, Inc. Tallahassee, Florida, U.S.A.) baited with a mixture of oats, peanut butter and fish. The sengis were sampled under permits issued by the CITES and Permit Management Office, Department of Environmental Affairs, Limpopo Province, South Africa (permit numbers: CPM333-00002, CPM-002-00002) and were maintained according to the guidelines of the animal ethics committee of the University of Pretoria (ethics clearance number: EC037-08). All males were housed in large polyurethane cages $(33 \mathrm{~cm} \times 33 \mathrm{~cm})$ with wood shavings for ground cover. In the laboratory, the animals were kept in a climate controlled room at a constant temperature of $25{ }^{\circ} \mathrm{C}$. They were fed with canned dog food (Promeal Ltd., Dassenberg, South Africa), Pronutro (high protein cereal; Pioneer Foods Ltd., Bokomo Foods, Cape Town, South Africa) and grated apples and carrots. Additionally, fresh water was provided in an open dish once daily and mealworms were offered once a week.

All 14 male sengis were initially subjected to a day-night cycle of eight hrs of light and 16 hrs of darkness (8L:16D; SD) for 40 days. Although all males were collected outside the male breeding season of E. myurus, the 40 days in SD acclimatises all individuals to the same conditions in the laboratory and may achieve maximum regression of the gonad in all males should the species be reproductively photoresponsive. Seven males sampled in February were then kept under the same light cycle for another 90 days. The seven males sampled in April and July were, however, subjected to a light cycle of 16L:8D (LD) for 90 days after the initial 40 days under SD photoperiodic conditions. The animals were weighed with a digital balance (Scout Pro SPU123, Ohaus Corporation, Pine Brook, New Jersey, U.S.A.) to the nearest $0.001 \mathrm{~g}$ at the onset and at the end of the experiment. At the conclusion of the experiments, all males were euthanized by an overdose of halothane. Blood was taken by exsanguinations from the heart, centrifuged at $3000 \mathrm{rpm}$ for $15 \mathrm{mins}$ and the plasma fraction was subsequently stored at -35 ${ }^{\circ} \mathrm{C}$ until hormone analysis. Testes were dissected out and fixed in Bouin's fluid for 
about $20 \mathrm{hrs}$ after which they were stored in $70 \%$ ethanol.

\section{Histology}

All excess tissue was removed before the testes were weighed to the nearest $0.01 \mathrm{mg}$ with a high precision scale (Ohaus Corp. Pine Brook, N.Y., U.S.A.). Testicular length and width $(\mathrm{mm})$ were measured with a pair of digital callipers (Sylvac Opto RS 232, Ultra Praezision Messzeuge $\mathrm{GmbH}$, Germany) to the nearest $0.01 \mathrm{~mm}$. Testicular volume $\left(\mathrm{mm}^{3}\right)$ was then calculated by using the formula for the volume of an ellipsoid: $V=4 / 3 \pi a b^{2}$, where $a$ represents half the maximum length and $b$ half the maximum width, as described by Woodall and Skinner (1989). The average mass (mg) and volume were calculated for both testes per male. Standard histological techniques were used to process the tissue after which the testes were cut into $7 \mu \mathrm{m}$ thick sections with a rotary microtome $(820$ Spencer, American Optical, Scientific Instrument Division, Buffalo, N.Y., U.S.A.) and mounted on microscope slides. Gelatine was used for mounting and the slides were oven-dried for about $48 \mathrm{hrs}$. The sections were then sequentially stained with Ehrlich's haematoxylin and eosin (Drury and Wallington 1967). Fifty round seminiferous tubules per testis per animal were photographed at $\times 10$ magnification with a digital camera (Moticam 1000 1.3 M Pixel USB 2.0) attached to a light microscope (Diaplan, Ernst Leitz Wetzlar GmbH, Germany). The diameter of the seminiferous tubules $(\mu \mathrm{m})$ was measured with the programme Motic Images Plus 2.0ML (Motic China Group, LTD., Xiamen, P.R. China) and the average of all diameters per individual male was calculated.

\section{Testosterone analysis}

Plasma testosterone concentration ( $\mathrm{ng} / \mathrm{dL}$ ) was measured with a coat-a-count hormone kit (Siemens Medical Solutions Diagnostics, Los Angeles, USA) for all 14 males. This method is based on a solid phase radioimmunoassay by which the amount of antibody bound radioactive labelled hormone is measured. The hormone concentration in the sample is subsequently calculated using a calibration curve. This assay was previously validated for $E$. myurus (Medger et al. 2012b). The intra-assay coefficient of variation was $4.3 \%$ and the interassay coefficient was $12.9 \%$.The minimum detectable amount of testosterone for the assay was $40.09 \mathrm{ng} / \mathrm{dL}$.

\section{Data analysis}

Body mass was compared before and after the experimental treatments with a repeated measures analysis of variance (ANOVA) and photoperiodic condition (either SD or LD) used as an in-between factor. Analysis of covariance (ANCOVA) was used to compare testicular mass, testicular volume, seminiferous tubule diameter and plasma testosterone concentration between the photoperiodic treatments. Body mass measured at the end of the experiments was used as a covariate to correct for any effects of body mass. The analysis on plasma testosterone concentration was performed on log-transformed data as this factor was not parametric. All statistical analyses were carried out with Statistical Package for the Social Sciences (SPSS) Statistics version 17.0 (Polar Engineering and Consulting 1993-2007). Data are given as mean \pm 1 standard deviation and results were found to be statistically significant at $P<0.05$.

\section{Results}

The reproductive system of male $E$. myurus does not seem to be regulated by changing photoperiods. Testicular mass and volume and seminiferous tubule diameter were not significantly different between $S D$ and $L D$ photoperiods $\left(F_{1,11}<2.49 ; P>0.14\right.$; Fig. $\left.1 \mathrm{~A}-\mathrm{C}\right)$. There was, however, a significant difference in plasma testosterone concentration between photoperiodic treatments $\left(F_{1,11}=5.40 ; P=0.04\right)$ with plasma testosterone being significantly higher in males subjected to SD than LD (Fig. 1D). Testicular mass, volume and plasma testosterone concentration were not significantly dependent on body mass $\left(F_{1,11} \leq\right.$ 0.19; $P \geq 0.67$ ). There was, however, a 
significant negative correlation between body mass and seminiferous tubule diameter $\left(F_{1,11}=\right.$ $6.01 ; P=0.03)$.

Males were significantly heavier at the end of the experiment than at the beginning $\left(F_{1,12}=9.79 ; P<0.01\right.$; Fig. 2$)$, but body mass was not significantly different between SD and LD photoperiods $\left(F_{1,12}=2.23 ; P=0.16\right.$; Fig. 2$)$. There was no interaction between body mass at the beginning and the end of the experiment and the photoperiodic treatments $\left(F_{1,12}=3.13\right.$; $P=0.10$; Fig. 2 ) indicating that body mass was not significantly influenced by photoperiod.

\section{Discussion}

Neal (1995) proposed that photoperiod may regulate seasonal reproduction in $E$. myurus because the start of the breeding season in this species is approximately a month following the winter solstice. In a previous study of seasonal reproduction in $E$. myurus (Medger et al. 2012b), we found that recrudescence of reproduction starts in May, about a month before the winter solstice. In the same study, we observed that male reproductive development was smallest in March and April (testes mass: $\sim 36 \mathrm{mg}$, testes volume: $\sim 29 \mathrm{~mm}^{3}$, seminiferous tubules: $\sim 138 \mu \mathrm{m}$ ) and at its maximum from July until October (testes mass: $\sim 93 \mathrm{mg}$, testes volume: $\sim 77 \mathrm{~mm}^{3}$ (both August), seminiferous tubules: $\sim 190 \mu \mathrm{m}$ (October); see also Medger et al., 2012b). From November until April, testosterone concentrations were very low and could not be measured in most individuals, whereas high concentrations were measured from June until August (average of $71 \mathrm{ng} / \mathrm{dL}$ in June; see also Medger et al., 2012b). This data suggests that the timing of reproduction by photoperiod in male E. myurus may not be as straightforward as suggested by Neal (1995). Contrary to Neal and our prediction, the present findings suggest that photoperiod is not the primary environmental cue regulating reproduction in male E. myurus.
Testicular mass, volume and seminiferous tubule diameters of male $E$. myurus were not affected by photoperiodic treatment. In addition, testes size and seminiferous tubule diameter for both photoperiodic treatments reached similar levels to those measured during the breeding season of E. myurus (see above, Medger et al., 2012b). A direct comparison between the two studies is possible because the same population of E. myurus was studied. This suggests that short-day photoperiods did not have the expected negative effect on reproductive development in this species. In fact, we observed the opposite for plasma testosterone concentration, which was increased in male $E$. myurus subjected to SD in comparison to LD photoperiods. In natural populations of E. myurus, testosterone concentrations start to increase in May during natural SD conditions (Medger et al. 2012b). This may suggest that SD photoperiods may have a stimulatory effect on the reproductive system of male $E$. myurus rather than an inhibitory, but given that no other significant differences were observed further studies are needed to confirm this suggestion.

The results of the present study suggest that reproduction is not influenced by photoperiod in E. myurus. Nevertheless, we have to consider that the SD individuals were subjected to the photoperiodic conditions for an extended time of about 19 weeks before reproduction was evaluated. Many photoresponsive animals regain their reproductive competence after prolonged exposure to inhibitory conditions such as shortday photoperiods or melatonin treatment. Spontaneous recrudescence of the gonads occurs after about 20 weeks in inhibitory conditions in hamsters (Bittman 1978; Steger et al. 1982) and 6 months in voles (Grocock 1980). After the 19 weeks exposure to shortday photoperiods, gonadal recrudescence could have occurred in male E. myurus, which may explain the lack of an inhibitory effect of SD photoperiods. Then again gonadal size was 
very similar in the two photoperiodic conditions and testosterone concentrations were even higher under SD photoperiods, whereas gonadal size should still be smaller under SD than LD, if recrudescence occurred recently. Nevertheless, future studies in sengis should consider the possibility of spontaneous recrudescence after prolonged exposure to inhibiting photoperiods. In addition, the different field histories of the individuals placed in the two photoperiodic treatments may have affected the results. Most animals were collected in one of two months, February or April. Both months are within the nonreproductive season of male $E$. myurus and testes size, seminiferous tubule diameter and testosterone concentrations were similar in the two months and smaller than during the breeding season (Medger et al. 2012b). Considering this, all males in the present study showed increased reproductive development in comparison to their original field conditions and independent of the respective photoperiodic conditions. Only one individual was collected from July and the parameters measured in that individual after photoperiod exposure were well within that of the individuals collected in the other two months. We cannot exclude that the slightly different field conditions experienced by the individuals collected in February, April and June affected the outcome of this study, but believe that this may have played only a minor role and has not affected the overall findings of this study.

Contrary to the findings in Medger et al. (2012b), Woodall and Skinner (1989) did not find seasonal differences in testes size, but they observed larger seminiferous tubules and increased spermatogenesis during the breeding season of $E$. myurus. These different results may indicate that male $E$. myurus retain some capacity to reproduce during some years or in some populations, whereas males may cease breeding entirely in more environmentally harsh conditions. Male E. myurus may exhibit a more opportunistic breeding strategy than previously reported and for which a distinctive photoperiodic regulation would be cumbersome. Further, most other sengi species breed aseasonally and only two other species are known to breed seasonally: the North African sengi (E. rozeti) (Séguignes 1989) and the bushveld sengi ( $E$. intufi) (Skinner and Chimimba 2005). In contrast to E. myurus, which breeds seasonally throughout its distributional range, E. intufi breeds seasonally in South Africa, but year-round in Namibia (reviewed in Skinner and Chimimba, 2005). Although reductions in reproduction have been observed during winter in some species (Neal 1995; Bernard et al. 1996), there does not appear to be a need to halt reproduction altogether in other sengis. Aseasonal reproduction is most likely an ancestral trait in sengis and seasonal reproduction may have developed later as an adaptation to severe seasonal environmental changes experienced by some species. Considering the large geographic distance separating the distributions of $E$. myurus and $E$. rozeti, it is also likely that seasonal reproduction developed separately in the two species. As such, seasonal reproduction may well be a more recent development in the Macroscelidea resulting in a reduced reliance on sophisticated time measuring systems to arise in the few seasonally breeding species and explaining the lack of photoperiodic effects on reproduction found in this study.

If photoperiod is not used to time reproduction in $E$. myurus, other environmental factors must regulate the seasonal reproduction of this species. Many tropical and sub-tropical rodents breed seasonally and it has been suggested that seasonal rainfall and the concomitant increase in food quantity and quality are the main factors which regulate seasonal reproduction at these low latitudes (Delany 1972; Neal 1986). Taylor and Green (1976), for example, found that rainfall and the availability of food regulates reproduction in African rodents, particularly in the Nile grass rat (Arvicanthis niloticus) and the Natal multimammate mouse 
(Mastomys natalensis). In contrast to most rodents, $E$. myurus is insectivorous and consumes primarily ants and termites (Churchfield 1987). Willis et al. (1992) observed that more termites were ingested by the aardvark (Orycteropus afer) in summer than in winter suggesting that termites are more readily available during the rainy season. It is likely that these food sources also either increase or are more accessible to the sengis after rainfall. Insect abundance would, therefore, increase during a period when the first young are born (see Medger et al., 2012b) and particularly high energetic demands have to be met by the mother during lactation (Speakman 2008). Male E. myurus may adjust their reproductive development to that of the female to ensure that the young are born during this time of maximum insect abundance. It is, however, unclear what the proximate cues that regulate reproduction in $E$. myurus may be as both rainfall and increased food availability occur after the onset of reproduction in this sengi (Medger et al. 2012b). Social factors and pair bonding may also be important for the regulation of seasonal reproduction in the monogamous $E$. myurus (Ribble and Perrin 2005). In the nonphotoresponsive Peromyscus aztecus, for example, males housed with females exhibited an increase in testes and epididymis mass and higher sperm counts and testosterone concentration compared to individually housed males (Demas and Nelson 1998).

Similar to the reproductive parameters assessed in the present study, the body mass of male E. myurus was not significantly different between the photoperiodic treatments. An effect of captivity was, however, apparent as the sengis gained body mass during the course of the experiment probably due to a lack of activity. It should, however, be noted that although not statistically significant, this effect was especially obvious under SD, but not under LD photoperiods indicating that day-length may affect body mass in $E$. myurus. An increase in body mass under SD photoperiod was demonstrated for collared lemmings (Dicrostonyx groenlandicus), which breed during the harsh winters in northern Canada and Greenland where the body mass gain is probably an adaptation to save energy by providing fat storage and increasing thermoregulatory ability (Hasler et al. 1976; Weil et al. 2006). In contrast, the body mass of male musk shrews from the tropics was observed to decrease under SD photoperiods (Rissman et al. 1987; Wayne and Rissman 1990). In E. myurus, an alteration of body mass with changing photoperiods may not be advantageous. However, the comparatively greater increase in body mass under a SD rather than LD photoperiod may indicate either a thermoregulatory or a fat storage capacity of body mass during the cold and dry winter.

In conclusion, reproductive development did not cease under SD photoperiods and, therefore, photoperiod may not be the primary cue which regulates seasonal reproduction in male $E$. myurus. However, although equivocal, there may be some evidence of photoperiodic effects that suggest that $E$. myurus may not be completely devoid of a photoperiodic time-measuring system and future studies should investigate the possibility of reproductive recrudescence after prolonged exposure to inhibitory conditions. Other environmental factors; especially food abundance and possibly social factors, may control seasonal reproduction in this sengi.

\section{Acknowledgements}

This research was funded by a South African Research Chair of Mammalian Behavioural Ecology and Physiology awarded to Nigel C. Bennett by the Department of Science and Technology and the South African National Research Foundation (NRF) and K. Medger acknowledges a doctoral grant from the NRF. The management and staff of Goro Game Reserve are acknowledged for permission to sample animals from the reserve and their support during this research. André Prins and 
Daniel Swanepoel are thanked for help during the field work and for collecting some of the animals.

\section{References}

Bernard, R.T.F., Kerley, G.I.H., Doubell, T., and Davison, A.. 1996. Reproduction in the round-eared elephant shrew (Macroscelides proboscideus) in the southern Karoo, South Africa. J. Zool. 240: 233-243.

Bittman, E.L. 1978. Hamster refractoriness: the role of insensitivity of pineal target tissues. Science 202: 648-650.

Bradshaw, W.E., and Holzapfel, C.M. 2007. Evolution of animal photoperiodism. Annu. Rev. Ecol. Evol. Syst. 38: 1-25. doi: 10.1146/annurev.ecolsys.37.091305.1101 15.

Bronson, F.H. 1985. Mammalian reproduction: an ecological perspective. Biol. Reprod. 32(1): 1-26.

Bronson, F.H. 2009. Climate change and seasonal reproduction in mammals. Phil. Trans. R. Soc. B 364: 3331-3340. doi: 10.1098/rstb.2009.0140.

Churchfield, S. 1987. A note on the diet of the rock elephant shrew, Elephantulus myurus, in Zimbabwe. J. Zool. 213: 743745.

Dark, J., Johnston, P.G., Healy, M., and Zucker, I. 1983. Latitude of origin influences photoperiodic control of reproduction of deer mice (Peromyscus maniculatus). Biol. Reprod. 28(1): 213-220.

Delany, M.J. 1972. The ecology of small rodents in tropical Africa. Mammal Rev. 2: 1-42.

Demas, G.E., and Nelson, R.J. 1998. Social, but not photoperiodic, influences on reproductive function in male Peromyscus aztecus. Biol. Reprod. 58(2): 385-389.

Drury, R.A.B., and Wallington, E.A. 1967. Carleton's histological technique. Oxford University Press, Oxford.

Grocock, C.A. 1980. Effects of age on photoinduced testicular regression, recrudescence, and refractoriness in the short-tailed field vole Microtus agrestis.
Biol. Reprod. 23:15-20.

Hasler, J.F., Buhl, A.E., and Banks, E.M. 1976. The influence of photoperiod on growth and sexual function in male and female collared lemmings (Dicrostonyx groenlandicus). J. Reprod. Fert. 46: 323329.

Heideman, P.D., and Bronson, F.H. 1994. An endogenous circannual rhythm of reproduction in a tropical bat, Anoura geoffroyi, is not entrained by photoperiod. Biol. Reprod. 50(3): 607-614.

Hoole, C., McKechnie, A.E., Parker, D.M., and Bennett, N.C., 2016. The influence of photoperiod on the reproductive physiology of the greater red musk shrew (Crocidura flavescens). Can. J. Zool. 94: 163-168. doi: 10.1139/cjz-2015-0128.

van der Horst, C.J. 1946. Some remarks on the biology of reproduction in the female of Elephantulus, the holy animal of Set. Trans. R. Soc. S. Afr. 31: 181-199.

Jackson, C., and Bernard, R.T.F. 1999. Short day length alone does not inhibit spermatogenesis in the seasonally breeding four-striped field mouse (Rhabdomys pumilio). Biol. Reprod. 60(6): 1320-1323.

Jackson, C., and Bernard, R.T.F. 2001. Gender differences in the inhibitory effects of a reduction in ambient temperature and a reduction in food quantity on reproduction in the southern African rodent, Rhabdomys pumilio. Reproduction 122: 385-395.

Lynch, G. R., Heath, H.W., and Johnston, C.M. 1981. Effect of geographical origin on the photoperiodic control of reproduction in the white-footed mouse, Peromyscus leucopus. Biol. Reprod. 25(3): 475-480.

Medger, K., Chimimba, C.T., and Bennett, N.C. 2012a. Reproductive photoresponsiveness in male spiny mice from South Africa. J. Zool. 286: 243-249. doi:10.1111/j.14697998.2011.00872.x.

Medger, K., Chimimba, C.T., and Bennett, N.C. $2012 \mathrm{~b}$. Seasonal reproduction in the eastern rock elephant-shrew: influenced 
by rainfall and ambient temperature? J. Zool. 288: 283-293. doi:10.1111/j.14697998.2012.00954.x.

Muteka, S.P., Chimimba, C.T., and Bennett, N.C. 2006. Reproductive photoresponsiveness in Aethomys ineptus and $A$. namaquensis (Rodentia: Muridae) from southern Africa. J. Zool. 268: 225-231. doi:10.1111/j.14697998.2005.00022.x.

Neal, B.R. 1986. Reproductive characteristics of African small mammals. Cimbebasia 8: 113-127.

Neal, B.R. 1995. The ecology and reproduction of the short-snouted elephant-shrew, Elephantulus brachyrhynchus, in Zimbabwe with a review of the reproductive ecology of the genus Elephantulus. Mammal Rev. 25(1/2): 5160.

Nelson, R.J., Frank, D., Smale, L., and Willoughby, S.B. 1989. Photoperiod and temperature affect reproductive and nonreproductive functions in male prairie voles (Microtus ochrogaster). Biol. Reprod. 40(3): 481-485.

Nelson, R. J., Marinovic, A.C., Moffatt, C.A., Kriegsfeld, L.J., and Kim, S. 1997. The effects of photoperiod and food intake on reproductive development in male deer mice (Peromyscus maniculatus). Physiol. Behav. 62(2): 945-950.

O'Brien, G.M., Curlewis, J.D., and Martin, L. 1993. Effect of photoperiod on the annual cycle of testis growth in a tropical mammal, the little red flying fox, Pteropus scapulatus. J. Reprod. Fert. 98: 121-127.

Paul, M.J., Zucker, I., and Schwartz, W. J. 2008. Tracking the seasons: the internal calendars of vertebrates. Phil. Trans. R. Soc. B 363: 341-361. doi: 10.1098/rstb.2007.2143.

Ribble, D.O., and Perrin, M.R. 2005. Social organization of the eastern rock elephantshrew (Elephantulus myurus): the evidence for mate guarding. Belg. J. Zool. 135 (suppl.): 167-173.

Rissman, E.F., Nelson, R.J., Blank, J.L., and Bronson, F.H. 1987. Reproductive response of a tropical mammal, the musk shrew (Suncus murinus), to photoperiod. J. Reprod. Fert. 81:563-566.

Séguignes, M. 1989. Contribution à l'étude de la reproduction d'Elephantulus rozeti (Insectivora, Macroscelididae). Mammalia 53(3): 377-386.

Skinner, J.D., and Chimimba, C.T. 2005. The mammals of the southern African subregion . 3rd edition. Cambridge University Press, Cambridge.

Speakman, J.R. 2008. The physiological costs of reproduction in small mammals. Phil. Trans. R. Soc. B 363: 375-398. doi:10.1098/rstb.2007.2145.

Steger, R.W., Bartke, A., and Goldman, B.D. 1982. Alterations in neuroendocrine function during photoperiod induced testicular atrophy and recrudescence in the golden hamster. Biol. Reprod. 26: 437-444.

Stevenson, K.T., van Tets, I.G., and Nay, L.A.I. 2009. The seasonality of reproduction in photoperiod responsive and nonresponsive northern red-backed voles (Myodes rutilus) in Alaska. Can. J. Zool. 87(2): 152-164. doi: 10.1139/Z08-147.

Taylor, K.D., and Green, M.G. 1976. The influence of rainfall on diet and reproduction in four African rodent species. J. Zool. 180: 367-389.

Wayne, N.L., and Rissman, E.F. 1990. Effects of photoperiod and social variables on reproduction and growth in the male musk shrew (Suncus murinus). J. Reprod. Fert. 89: 707-715.

Weil, Z.M., Martin II, L.B., and Nelson, R.J. 2006. Photoperiod differentially affects immune function and reproduction in collared lemmings (Dicrostonyx groenlandicus). J. Biol. Rhythms 21(5): 384-393.

doi: $10.1177 / 0748730406292444$.

Willis, C.K., Skinner, J.D., and Robertson, H.G. 1992. Abundance of ants and termites in the False Karoo and their importance in the diet of the aardvark Orycteropus afer. Afr. J. Ecol. 30(4): 322-334. doi: 
10.1111/j.1365-2028.1992.tb00509.x. Woodall, P.F., and Skinner, J.D. 1989. Seasonality of reproduction in male rock elephant shrews, Elephantulus myurus. J. Zool. 217: 203-212. 

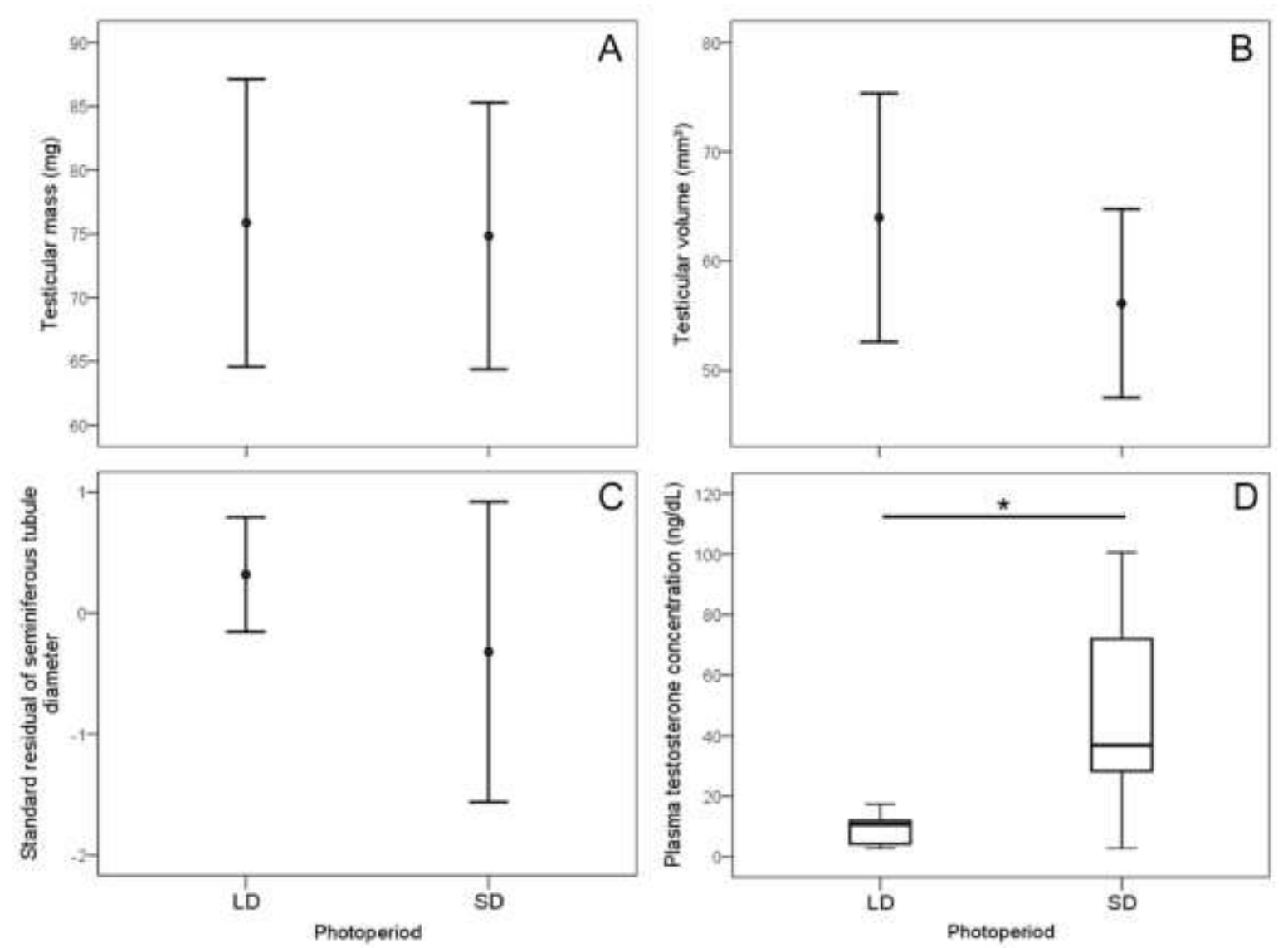

Fig. 1. Testicular mass ( $\mathrm{mg} ; \mathrm{A})$, volume $\left(\mathrm{mm}^{3} ; \mathrm{B}\right)$ and standardized residual of seminiferous tubule diameter $(\mu \mathrm{m})$ by body mass $(\mathrm{g} ; \mathrm{C})$ of male eastern rock sengis (Elephantulus myurus) from South Africa compared between long-day (LD) and short-day (SD) photoperiodic treatments. The results are mean \pm standard deviation. The box-plots (D) show the median, lower and upper quartile and their 1.5 interquartile ranges for plasma testosterone concentrations (ng/dL) of males exposed to LD and SD photoperiods. The asterisk indicates a significant comparison $(P<0.05)$. 


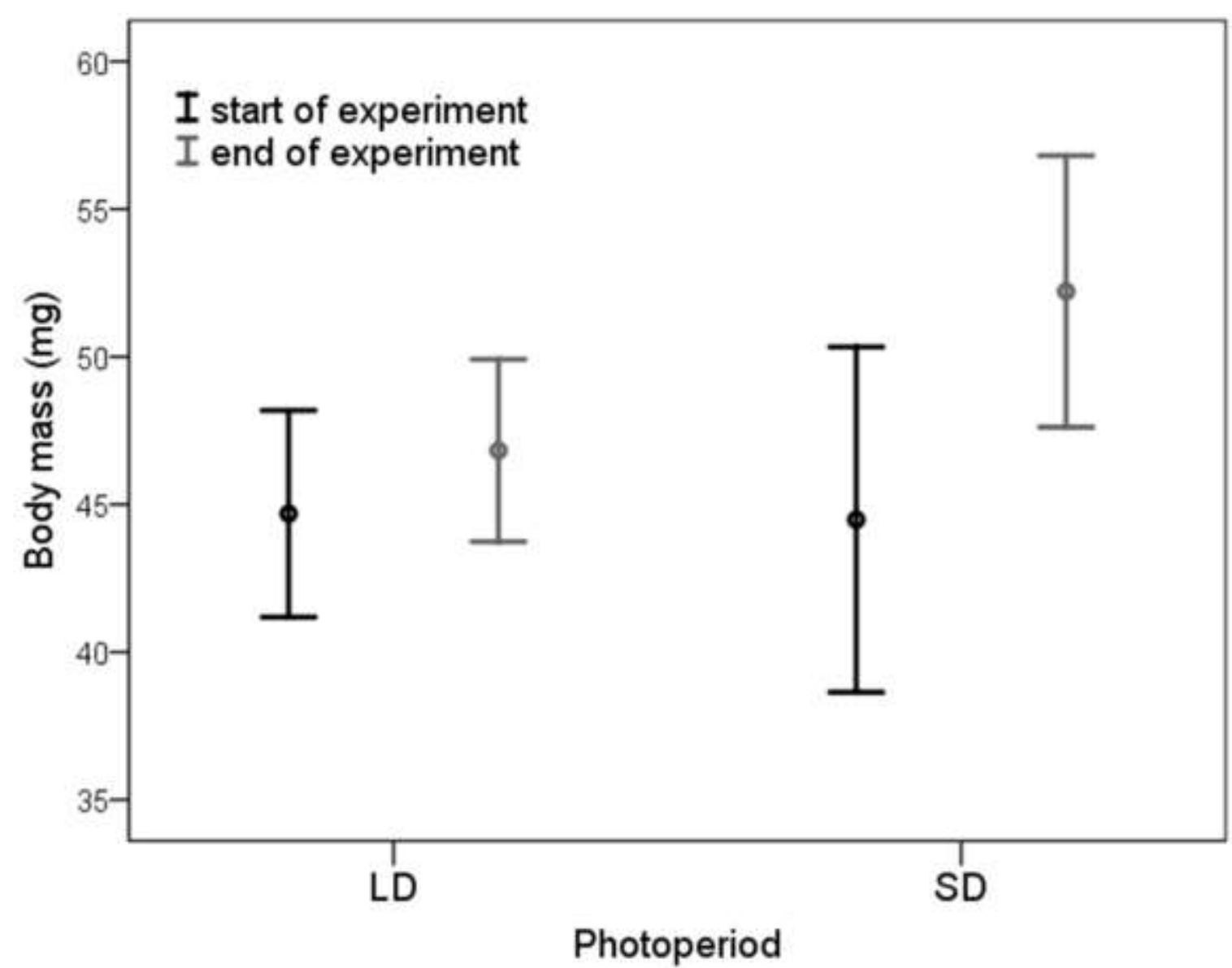

Fig. 2. Mean body mass $(\mathrm{g}) \pm$ standard deviation of male eastern rock sengis (Elephantulus myurus) from South Africa displayed between long-day (LD) and short-day (SD) photoperiodic treatments and compared between the start and the end of the experiment. 